\title{
Growth cycle-induced changes in sensitivity of Staphylococcus aureus to bactericidal lipids from abscesses
}

\author{
ZHUO XIONG, S. GE, N. R. CHAMBERLAIN* and F. A. KAPRAL $\dagger$ \\ Department of Medical Microbiology and Immunology, The Ohio State University, Columbus, Ohio 43210 \\ and * The Kirksville College of Osteopathic Medicine, Kirksville, MO 63501, USA
}

\begin{abstract}
Summary. Three Staphylococcus aureus strains (303, $18 \mathrm{Z}$ and TG), exhibiting various patterns of survival within abscesses, were significantly more sensitive to the bactericidal activity of oleic acid during the log phase of growth than at other stages of the growth cycle. Cells entering the stationary phase showed diminished sensitivity to the fatty acid. These changes were reflected by changes in the LD50 and also by differences in the rate of killing by oleic acid. Additional changes were noted: the rate of killing by oleic acid declined over a 4-day period; a progressively greater proportion of the staphylococcal population became resistant to even high concentrations of oleic acid; from the fourth day onwards $c$. 50-55\% of the cocci were totally resistant to the fatty acid. Strains 303 and $18 \mathrm{Z}$ became more sensitive to mono-olein during the log phase of growth, but strain TG was very resistant to mono-olein throughout the growth cycle. Growth in the presence of glycine $6 \%$ to reduce cross-links in the peptidoglycan did not alter bacterial sensitivity to oleic acid. However, all three $S$. aureus strains exhibited significant increases in membrane fluidity during the log phase of growth, but upon entering the stationary phase membrane fluidity again decreased. Concomitant changes in carotenoid content occurred during the growth cycle, but these changes did not appear to be solely responsible for the changes in sensitivity to the lipids.
\end{abstract}

\section{Introduction}

A decade ago, we first detected a novel host defence mechanism in abscesses caused by Staphylococcus aureus. ${ }^{1-3}$ This mechanism is based upon the production by the host of two types of bactericidal lipid-a pool of monoglycerides, and a pool of longchain unsaturated fatty acids. ${ }^{3-5}$ These lipids are generated in abscesses by two independent mechanisms. ${ }^{3,5}$ Only the long-chain $\left(\mathrm{C}_{14}-\mathrm{C}_{20}\right)$ unsaturated fatty acids produced in abscesses are bactericidal for $S$. aureus. The monoglycerides produced by the host are the 2-monoglycerides, but these spontaneously isomerise to form the corresponding 1-monoglycerides. Whereas the bactericidal fatty acids collectively make up c. $20 \%$ of the total lipid pool in abscesses, the monoglycerides comprise $<0 \cdot 1 \%$.

Staphylococci exhibit three basic patterns of survival within abscesses. ${ }^{6,7}$ With some strains, elimination begins as soon as the bactericidal lipids are mobilised and continues unabated (immediate elimination pattern), whereas other strains can persist for months (persistent pattern). Still others are eliminated, but only after a delay of $c$. 10 days (delayed elimination pattern). Phagocytosis does not occur within the abscesses. There are no intact leucocytes near the core where the cocci are located, and cocci are not found at the periphery where viable leucocytes are located. However, the survival pattern of a strain is related to its sensitivity to the 2-monoglycerides. ${ }^{5}$

Certain factors can alter a strain's sensitivity to the bactericidal lipids. The presence of a capsule, although rare among $S$. aureus strains, can confer a two-to-fourfold increase in resistance to the bactericidal lipids. ${ }^{8}$ Prior growth in glucose increases a strain's resistance to monoglycerides 50 -fold, but does not alter its sensitivity to the fatty acids. ${ }^{9,10}$ In contrast, low pigment (carotenoid) levels are associated with increased sensitivity to the fatty acids, but do not affect sensitivity to monoglycerides. ${ }^{11}$ Reduced carotenoid levels are also associated with an increase in membrane fluidity and these alterations in membrane fluidity may account for the changes in sensitivity to the fatty acids. ${ }^{12}$

Preliminary studies suggested that staphylococci might also differ in sensitivity to these lipids at different states of the growth cycle. To evaluate this possibility, three $S$. aureus strains were harvested at different stages of the growth cycle and tested for sensitivity to mono-olein and oleic acid. 


\section{Materials and methods}

\section{Bacterial strains}

S. aureus strains $303,18 \mathrm{Z}$ and TG were selected for this study on the basis of their characterisation in previous studies. ${ }^{1,2,6,7}$ Strain 303 is immediately eliminated from abscesses, strain $18 \mathrm{Z}$ shows delayed elimination and strain TG is persistent in abscesses. Strains 18Z-1 and 18Z-2 are two non-pigmented mutants derived from the parent $18 \mathrm{Z}$ strain. ${ }^{11}$

\section{Medium}

Trypticase yeast extract broth (TYB) consisting of trypticase peptone $1.7 \%$, yeast extract $1 \%, \mathrm{NaCl}$ $0.5 \%$ and dibasic potassium phosphate $0.25 \%$ was used throughout.

\section{Staphylococcal suspensions}

Overnight starter cultures in TYB were diluted 1 in 100 in fresh TYB and incubated at $37^{\circ} \mathrm{C}$ with agitation to establish the growth kinetics for each strain. Subsequently, fresh cultures were prepared, absorbance measurements at $630 \mathrm{~nm}$ were taken to verify the stage of the growth cycle and samples were removed at various times. The organisms were diluted in TYBsaline (saline with TYB $8 \%$ ), sealed in ampoules and stored at $-20^{\circ} \mathrm{C}$ until required.

\section{Bactericidal assay}

Oleic acid and mono-olein were selected as representative bactericidal lipids because they are the most prominent components of the fatty acid and monoglyceride pools which accumulate in abscesses. ${ }^{2,5}$ Bactericidal activity was assayed as described previously. ${ }^{2}$ Briefly, a stock solution of either lipid in ethanol was prepared and diluted 1 in 10 in diluent $(2 \mathrm{M} \mathrm{NaCl}$ with $2 \mathrm{~mm}$ EDTA) just before use. Additional serial two-fold dilutions of the suspensions were made in diluent and a standard number of the organisms being tested (in diluent) was added to each dilution. After incubation of the tubes in a water bath at $37^{\circ} \mathrm{C}$ for $1 \mathrm{~h}$ with shaking, a $0.5-\mathrm{ml}$ sample was removed from each tube and plated on trypticase soy agar (TSA) to count the number of surviving cocci. Several control tubes containing organisms and diluent only were included in each assay. All assays were done in duplicate. The LD50 was determined by the method of probits ${ }^{13}$ and was expressed as $\mu \mathrm{g} / \mathrm{ml}$. Statistical evaluation of the different strains was done by Student's $t$ test.

\section{Killing rates}

Staphylococcal suspensions were appropriately diluted in diluent ( $2 \mathrm{M} \mathrm{NaCl}$ with $2 \mathrm{~mm}$ EDTA) as for the bactericidal assay. The diluted suspension was incubated at $37^{\circ} \mathrm{C}$ with shaking, and a pre-determined amount of oleic acid was added. At zero time and every $10 \mathrm{~min}$ thereafter, samples were removed and plated on TSA to count the number of surviving organisms. Suspensions incubated without the fatty acid served as controls.

\section{Fluorescence polarisation values}

Staphylococci harvested at different stages of the growth cycle were washed once in saline, resuspended in saline with glycerol $20 \%$, and stored at $-70^{\circ} \mathrm{C}$. At time of use the suspensions were suspended in saline containing $2 \mu \mathrm{M}$ 1,6-diphenyl-1,3,5-hexatriene to give an $\mathrm{A}_{600 \mathrm{~nm}}$ of 0.300 (SD 0.005), and then incubated at $37^{\circ} \mathrm{C}$ for at least $30 \mathrm{~min}$. Polarisation values were obtained in an SLM Aminco 8000C fluorimeter (excitation $365 \mathrm{~nm}$; emission $425 \mathrm{~nm}$ ). Data were acquired at $37^{\circ} \mathrm{C}$ and polarisation values were calculated by software provided by SLM. ${ }^{12}$

Statistical analysis for comparing the difference in mean polarisation value was performed by oneway analysis of variance (ANOVA) to determine differences in the group and Bonferroni's post test to determine where the differences in the group occurred. ${ }^{14}$

\section{Carotenoid extraction and quantification}

Staphylococcal carotenoids (pigments) were extracted and quantified as previously described. ${ }^{12}$ In some cases carotenoids were separated by thin-layer chromatography and individually quantified spectrophotometrically at their absorption maximum as described by Marshall and Wilmoth. ${ }^{15}$

\section{Alteration of cell wall structure}

Studies by Hammes et al. ${ }^{16}$ have shown that growth of $S$. aureus in the presence of high concentrations of glycine leads to a more loosely cross-linked peptidoglycan. Accordingly, S. aureus strains 303, $18 \mathrm{Z}$ and TG were grown in media with different concentrations of glycine. The effect of glycine was assessed by the presence of swollen cells and changes in $A_{630 \mathrm{~nm}}$ measurements. Subsequently, the organisms were grown in medium with $0.8 \mathrm{M}$ glycine and harvested after $45 \mathrm{~min}, 2 \mathrm{~h}$, and $48 \mathrm{~h}$. Organisms grown similarly in medium without added glycine served as controls. The organisms were assayed for sensitivity to the lipids as described previously.

\section{Results}

\section{Sensitivity to bactericidal lipids}

S. aureus strains $303,18 \mathrm{Z}$ and TG became more sensitive to oleic acid as they entered the log phase, but upon entering the stationary phase they again became more resistant (table I). The ratio between maximum sensitivity (log phase) and minimum sensitivity (stationary phase) was at least 260 -fold for strain 303 and 18-20-fold for strains $18 \mathrm{Z}$ and TG.

$S$. aureus strains $303,18 \mathrm{Z}$ and TG were also examined for their sensitivity to mono-olein. Strain 
Table I. Sensitivity of $S$. aureus strains to oleic acid at different stages of growth cycle

\begin{tabular}{|c|c|c|c|}
\hline \multirow{2}{*}{$\begin{array}{l}\text { Stage of } \\
\text { growth cycle }\end{array}$} & \multicolumn{3}{|c|}{ Oleic acid LD50 (SE) for strain } \\
\hline & 303 & $18 \mathrm{Z}$ & TG \\
\hline $0 \mathrm{~h}$ & $0.58(0.63)$ & $0.81(0.44)$ & $3.45(0.49)$ \\
\hline Early $\log (0.5 \mathrm{~h})$ & $0.14(0.11)$ & $0.32(0.12)$ & $1 \cdot 12(0.72)$ \\
\hline Early $\log (1.0 \mathrm{~h})$ & $0.095(0.035)$ & $0.23(0.095)$ & $0.34(0.26)$ \\
\hline Mid-log $(1.5 h)$ & $0.099(0.076)$ & $0 \cdot 18(0.074)$ & $0.22(0.07)$ \\
\hline Late $\log (2 \mathrm{~h})$ & - & $0 \cdot 21$ & - \\
\hline Early stationary $(4 \mathrm{~h})$ & - & $0 \cdot 39$ & - \\
\hline Early stationary $(6 \mathrm{~h})$ & 0.29 & $1 \cdot 23$ & $0 \cdot 44$ \\
\hline Stationary $(10 \mathrm{~h})$ & - & $3 \cdot 3$ & $2 \cdot 1$ \\
\hline Stationary $(12 \mathrm{~h})$ & 1.83 & $15 \cdot 1$ & $3 \cdot 5$ \\
\hline Stationary $(24 \mathrm{~h})$ & $>25$ & $>25$ & $4 \cdot 5$ \\
\hline Late stationary $(48 \mathrm{~h})$ & - & $>25$ & - \\
\hline
\end{tabular}

$\mathrm{LD} 50, \mu \mathrm{g} / \mathrm{ml}$ (average of three-to-five assays).

Table II. Sensitivity of $S$. aureus strains to mono-olein at different stages of growth cycle

\begin{tabular}{l|ccc}
\hline & \multicolumn{3}{|c}{ Mono-olein LD50 for strain } \\
\cline { 2 - 4 } $\begin{array}{l}\text { Stage of } \\
\text { growth cycle }\end{array}$ & 303 & $18 \mathrm{Z}$ & TG \\
\hline Mid-log (1.5 h) & $0 \cdot 42$ & $9 \cdot 8$ & $>25$ \\
Early stationary (6 h) & $2 \cdot 9$ & $>25$ & $>25$ \\
Stationary (10 h) & $>25$ & - & $>25$ \\
Stationary (12 h) & $>25$ & $>25$ & $>25$ \\
Stationary (24 h) & $>25$ & $>25$ & $>25$ \\
Late stationary (48 h) & $>25$ & $>25$ & $>25$ \\
\hline
\end{tabular}

$\mathrm{LD} 50, \mu \mathrm{g} / \mathrm{ml}$ (average of two-to-four assays).

303 was decidedly more sensitive to mono-olein during the log phase than during the stationary phase (table II). The ratio between maximum and minimum sensitivity was at least 60 -fold. Strain $18 \mathrm{Z}$ was moderately sensitive at mid-log phase, but by $6 \mathrm{~h}$ was fully resistant to mono-olein and remained so for the remainder of the growth cycle. No such differences were detected with strain TG which was quite resistant to monoolein throughout.

\section{Changes in killing rates}

S. aureus 303 harvested during the log phase of growth was killed rapidly by oleic acid $(6.25 \mu \mathrm{g} / \mathrm{ml})$ and $<0.5 \%$ of the population survived after $10 \mathrm{~min}$ (fig. 1). With cocci recovered during the late stationary phase $(24 \mathrm{~h})$, the rate of killing was markedly reduced, but c. $99 \%$ of the cocci were still destroyed within $1 \mathrm{~h}$. However, no further reductions were seen with additional incubation. Bacteria harvested later (2-7 days), were killed even more slowly (fig. 1), but a progressively greater proportion of the population was resistant to this and even greater concentrations of oleic acid (fig. 2). Similar results were obtained with $S$. aureus strains $18 \mathrm{Z}$ and $\mathrm{TG}$.

\section{Alteration of cell walls and sensitivity to lipids}

To see whether the differences in sensitivity might be due to changes in cell-wall integrity, we attempted to weaken the cell walls by growing the staphylococci in the presence of high glycine levels. With all three strains, growth was altered by glycine 4-6\%. With glycine $6 \%$, growth proceeded normally for 3-4 h, but then the $A_{630 n m}$ decreased until 18-24 h. During this period swollen cells were evident. Thereafter, growth resumed and continued until the usual maximum cell density was attained at $48 \mathrm{~h}$. Consequently, organisms were harvested after $45 \mathrm{~min}, 2 \mathrm{~h}$ and $48 \mathrm{~h}$ and assayed for their lipid sensitivity. Although organisms harvested after $45 \mathrm{~min}$ and $2 \mathrm{~h}$ were more sensitive than

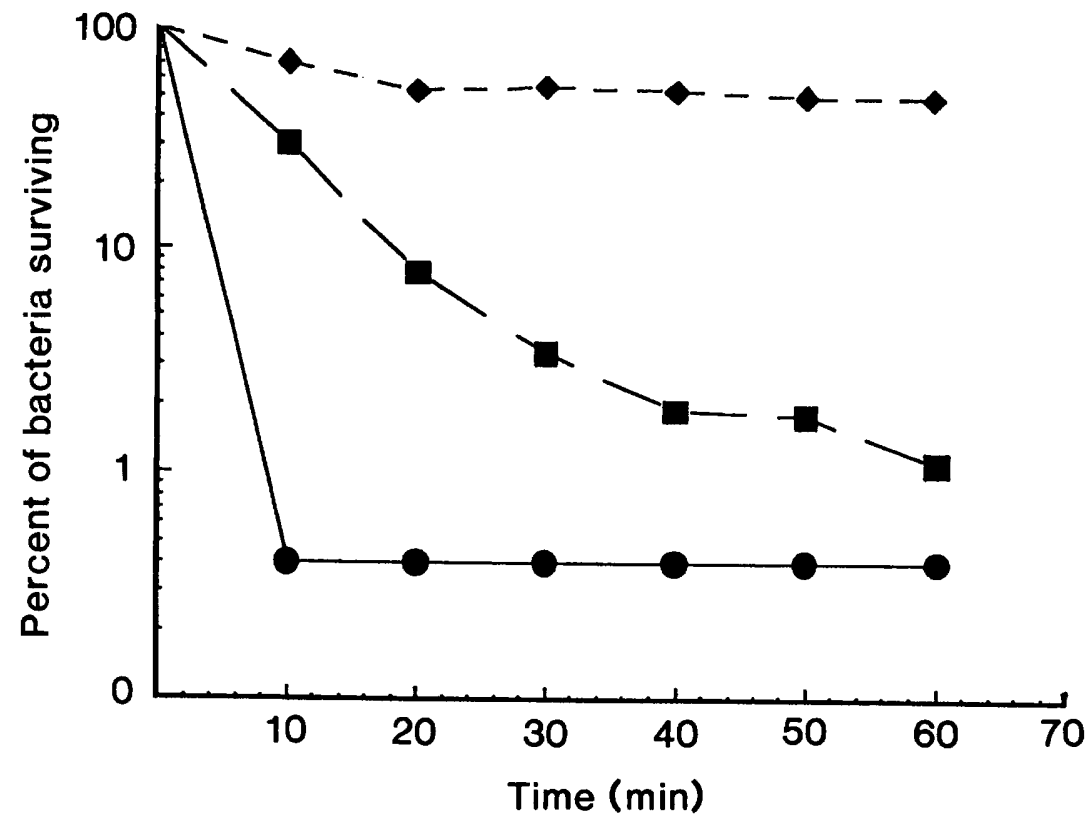

Fig. 1. The rate of killing by oleic acid $6.25 \mu \mathrm{g} / \mathrm{ml}$ of $S$. aureus 303 harvested at different times during the growth cycle. Only representative times are shown: $1.5 \mathrm{~h}(\mathrm{O}), 24 \mathrm{~h}(\mathrm{Q})$ and $96 \mathrm{~h}(\bullet)$. No further killing occurred after incubation for $1 \mathrm{~h}$. 


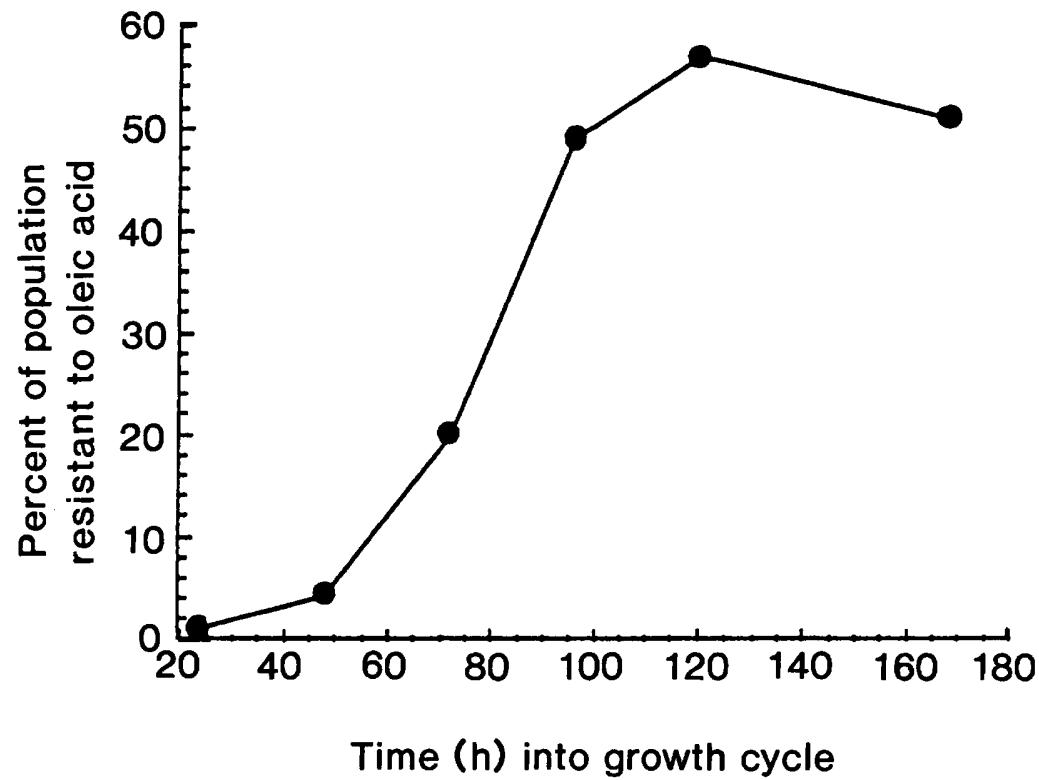

Fig. 2. Proportion of $S$. aureus 303 resistant to oleic acid $6 \cdot 25 \mu \mathrm{g} / \mathrm{ml}$ when harvested at different times during the growth cycle. The cocci surviving incubation for $1 \mathrm{~h}$ were resistant to this and to higher concentrations of oleic acid.

Table III. Membrane fluidity in S. aureus

\begin{tabular}{|c|c|c|c|}
\hline \multirow{2}{*}{$\begin{array}{l}\text { Stage of } \\
\text { growth cycle }\end{array}$} & \multicolumn{3}{|c|}{ Polarisation value (SD) for strain } \\
\hline & 303 & $18 \mathrm{Z}$ & TG \\
\hline & $0.367(0.008)$ & $0 \cdot 3522(0 \cdot 0065)$ & $0 \cdot 384(0 \cdot 002)$ \\
\hline Mid-log $(1.5 \mathrm{~h})$ & $0.346(0.004)^{*}$ & $0.3162(0.0040)^{*}$ & $0.364(0.006) \dagger$ \\
\hline Early stationary $(6 \mathrm{~h})$ & $0.368(0.005)$ & $0.3556(0.0072)$ & $0.356(0.005) \dagger$ \\
\hline Stationary $(12 \mathrm{~h})$ & $0.365(0.003)$ & $0.3747(0.0053)$ & $0.388(0.005)$ \\
\hline Stationary $(24 \mathrm{~h})$ & $0.367(0.008)$ & $0.3774(0.0053)$ & $0.384(0.002)$ \\
\hline
\end{tabular}

* Significantly different from time 0 and $6 \mathrm{~h}(\mathrm{p}=0.01)$.

$\uparrow$ Significantly different from time 0 and $12 \mathrm{~h}(\mathrm{p}=0.001)$, but not different from each other.

organisms harvested at $48 \mathrm{~h}$, there was no difference in sensitivity between organisms grown in the presence and absence of glycine.

\section{Changes in membrane fluidity}

Since previous studies had indicated that an increase in membrane fluidity was associated with increased sensitivity to the bactericidal fatty acids, ${ }^{12}$ the strains were examined for any changes in membrane fluidity during the different stages of the growth cycle. $S$. aureus strains 303, $18 \mathrm{Z}$ and TG all exhibited an increase in membrane fluidity while growing exponentially $(90 \mathrm{~min})$, but fluidity returned to baseline values thereafter (table III). In the case of strains 303 and $18 \mathrm{Z}$, the polarisation values evident at $90 \mathrm{~min}$ were significantly different from values obtained at zero time or $6 \mathrm{~h}(\mathrm{p}=0.01)$. With strain TG, the values at $90 \mathrm{~min}$ and $6 \mathrm{~h}$ were significantly different from those at zero time and $12 \mathrm{~h}(\mathrm{p}=0.001)$ but were not different from each other.

\section{Changes in carotenoid levels}

Because reduced levels of carotenoids are associated with increased membrane fluidity and increased sen-
Table IV. Carotenoid content* of $S$. aureus strains $303,18 \mathrm{Z}$ and TG when harvested at various times of the growth cycle

\begin{tabular}{c|ccc}
\hline \multirow{2}{*}{$\begin{array}{c}\text { Stage of } \\
\text { growth } \\
\text { cycle (h) }\end{array}$} & \multicolumn{3}{|c}{$\mathrm{A}_{\mathbf{4 6 4}}( \pm \mathrm{SD})$ for strain } \\
\cline { 2 - 4 } & 303 & \multicolumn{3}{|c}{$18 \mathrm{Z}$} & $\mathrm{TG}$ \\
\hline 0 & $0.174(0.058) \dagger$ & $0.184(0.10) \dagger$ & $0.152(0.049) \dagger$ \\
1.5 & $0.094(0.0096)$ & $0.044(0.012)$ & $0.039(0.0033)$ \\
6 & $0.159(0.092)$ & $0.148(0.013) \dagger$ & $0.121(0.063) \dagger$ \\
12 & $0.305(0.095) \dagger$ & $0.416(0.199) \dagger$ & $0.182(0.064) \dagger$ \\
24 & $0.411(0.087) \dagger$ & $0.892(0.151) \dagger$ & $0.227(0.109) \dagger$ \\
& & & \\
\hline
\end{tabular}

* In $0.25 \mathrm{~g}$ wet weight of cells.

$\dagger$ Statistically significant from $1.5-\mathrm{h}$ values $(\mathrm{p}=<0.05)$.

sitivity, ${ }^{12}$ the total amounts of carotenoids present throughout the life cycle were measured to see whether this could explain the changes in sensitivity to oleic acid. All three strains had significant reductions in carotenoid content during the exponential phase, but as the organisms entered the stationary phase the carotenoid levels again increased (table IV).

If changes in the amounts of carotenoids were solely responsible for the changes in sensitivity to oleic acid, carotenoid-negative mutants should show little or no 
Table V. Sensitivity of carotenoid-negative mutants to bactericidal lipids in abscesses

\begin{tabular}{|c|c|c|c|c|}
\hline \multirow{2}{*}{$\begin{array}{l}\text { Stage of } \\
\text { growth } \\
\text { cycle } \\
\text { (h) }\end{array}$} & \multicolumn{2}{|c|}{$\begin{array}{l}\text { Oleic acid LD50 } \\
\text { for strain }\end{array}$} & \multicolumn{2}{|c|}{$\begin{array}{l}\text { Mono-olein LD50 } \\
\text { for strain }\end{array}$} \\
\hline & $18 \mathrm{Z}-1$ & $18 \mathrm{Z}-2$ & $18 \mathrm{Z}-1$ & $18 Z-2$ \\
\hline 1.5 & 0.094 & 0.054 & $1 \cdot 36$ & 0.52 \\
\hline 6 & $1 \cdot 36$ & $0 \cdot 15$ & $>25$ & $16 \cdot 4$ \\
\hline 12 & $14 \cdot 2$ & $0 \cdot 31$ & $>25$ & $14 \cdot 1$ \\
\hline 24 & 17.0 & $2 \cdot 1$ & $>25$ & $>25$ \\
\hline 48 & 1.70 & 0.32 & $>25$ & $10 \cdot 6$ \\
\hline
\end{tabular}

LD50, ${ }^{*} \mu \mathrm{g} / \mathrm{ml}$ (average of two-to-four assays).

change in sensitivity to oleic acid throughout the growth cycle. Consequently, two colourless mutants of $S$. aureus $18 \mathrm{Z}$ (colour index 0 ) which had been isolated in another study ${ }^{11}$ were examined. Carotenoids were collected, extracted and quantified from $c .20 \mathrm{~g}$ of each organism. Strain $18 \mathrm{Z}-1$ contained only $1.02 \%$ as much carotenoid as the parent strain $18 \mathrm{Z}$ and strain $18 \mathrm{Z}-2$ only $0.79 \%$ as much. In both cases, the only carotenoid present was the colourless 4,4'-diapophytofluene, which is the initial triterpenoid intermediate in the biosynthetic pathway. ${ }^{17}$ Subsequently these mutants were harvested at different times in the growth cycle and assayed for sensitivity to oleic acid and monoolein.

These mutants were both more sensitive to oleic acid during the log phase than during the stationary phase (table V). Maximum resistance occurred at $24 \mathrm{~h}$, but by $48 \mathrm{~h}$ the organisms were becoming more sensitive again. The ratio between maximum sensitivity (log phase) and minimum sensitivity ( $24 \mathrm{~h})$ was 181 for strain $18 \mathrm{Z}-1$ and 39 for strain 18Z-2.

\section{Discussion}

Three S. aureus strains were decidedly more sensitive to oleic acid during the exponential phase than at any other time in the growth cycle. This increased sensitivity was reflected by changes in both the LD50 and the rate of killing (table I, fig. 1). Concomitant increases in membrane fluidity and decreases in carotenoid levels were also seen at this time (table III). Previous studies had already noted a relationship between sensitivity to fatty acids and carotenoid levels. ${ }^{11}$ In this case, $S$. aureus mutants deficient in carotenoid production or pigmented strains grown under conditions minimising pigment content were found to be more sensitive to oleic acid and also showed an increase in membrane fluidity. Again, these changes were manifest through changes in both the LD50 and the killing rate. ${ }^{11,12}$

While it may be argued that the increased sensitivity to the lipids during the log phase is due to an increase in membrane fluidity resulting from a reduction in the carotenoid content, our data suggest that this is not the only explanation. The carotenoid-negative mutants, $18 \mathrm{Z}-1$ and $18 \mathrm{Z}-2$, possessing only $c .1 \%$ of the carotenoid content of the parent strain, still showed substantial differences in sensitivity to the lipids at various stages of the growth cycle (table V). As was expected, the mutants were somewhat more sensitive to oleic acid than the parent strain 18Z; nevertheless, additional growth cycle-related changes were evident. It is possible that the remaining $1 \%$ of $4,4^{\prime}$ diapophytofluene could be further reduced during the log phase and thus account for the changes in sensitivity. However, this does not seem likely because the ratio of sensitivity between non-pigmented mutants and fully pigmented parent strains was only about five-fold, ${ }^{11}$ whereas the ratio of maximum sensitivity and minimum sensitivity during the growth cycle was in the range 39-181 (table V).

Upon entering the stationary phase $S$. aureus survives for long periods without dying. Nevertheless, when harvested at various times during the stationary phase the organisms continued to change in their response to oleic acid, as evidenced by further reductions in the rate of killing and the fact that an increasing fraction of the population became resistant to high concentrations of the fatty acid (figs. 1 and 2). These responses appear unrelated to membrane fluidity, but the basis for this population change is not known. In any case, the stationary phase should not be treated as a period of metabolic inactivity. Numerous studies have shown that during the stationary phase gram-negative bacteria can undergo changes in membrane composition and cell-wall structure, and thereby become more resistant to different environmental stresses $;{ }^{18}$ similar changes might also occur in grampositive organisms.

This study was supported by Public Health Service grant AI19879 from the National Institute of Allergy and Infectious Diseases and grants to N.R.C. from The Charles and Jennie Fermaturo Foundation. The authors wish to thank G. Vickers for technical assistance in measuring carotenoid levels.

\section{References}

1. Dye ES, Kapral A. Partial characterization of a bactericidal system in staphylococcal abscesses. Infect Immun 1980; 30: 198-203.

2. Dye ES, Kapral FA. Characterization of a bactericial lipid developing within staphylococcal abscesses. Infect Immun $1981 ; 32$ : 98-104.

3. Kapral FA. A novel host defense mechanism controlling the

survival of Staphylococcus aureus in focal lesions. In: Jeljaszewicz J, Ciborowski P (eds) The staphylococci. NY, Gustav Fischer Verlag. 1990: 68-74.

4. Shryock TR, Dye, ES, Kapral FA. The accumulation of bactericidal lipids in staphylococcal abscesses. $J$ Med Microbiol 1992; 36: 332-336.

5. Engler HD, Kapral FA. The production of a bactericidal monoglyceride in staphylococcal abscesses. $J$ Med Microbiol 1992; 37: 238-244. 
6. Kapral FA, Godwin JR, Dye ES. Formation of intraperitoneal abscesses by Staphylococcus aureus. Infect Immun 1980; 30: 204-211.

7. Dye ES, Kapral FA. The survival of Staphylococcus aureus in intraperitoneal abscesses. J Med Microbiol 1981; 14: 185-194.

8. Mortensen JE, Kapral FA. Effect of capsulation on the resistance of Staphylococcus aureus to the bactericidal lipids produced in abscesses. $J$ Med Microbiol 1992; 36: 337-340.

9. Kapral FA. Factors influencing the sensitivity of Staphylococcus aureus to the bactericidal lipids produced in abscesses. In: Jelijaszewicz J, Ciborowski P (eds) The staphylococci. NY, Gustav Fischer Verlag. 1990: 240-246.

10. Harvey KM, Hart J, Kapral FA. Staphylococcal intraperitoneal abscesses in diabetic mice. In: Jeljaszewicz J, Ciborowski P (eds) The staphylococci. NY, Gustav Fischer Verlag. 1990: 218-219.

11. Xiong Z, Kapral FA. Carotenoid pigment levels in Staphylococcus aureus and sensitivity to oleic acid. $J$ Med Microbiol 1992; 37: 192-194.
12. Chamberlain NR, Mertens BG, Xiong Z, Kapral FA, Boardman JL, Rearick JI. Correlation of carotenoid production, decreased membrane fluidity, and resistance to oleic acid killing in Staphylococcus aureus 18Z. Infect Immun 1991; 59: 4332-4337.

13. Finney DJ. Probit analysis, 3rd edn. Cambridge, Cambridge University Press. 1971.

14. Day AW, Quinn GP. Comparisons of treatments after an analysis of variance in ecology. Ecol Monogr 1989; 59: 433-463.

15. Marshall JH, Wilmoth GJ. Pigments of Staphylococcus aureus, a series of triterpenoid carotenoids. J Bacteriol 1981; 147: 900-913.

16. Hammes W, Schleifer KH, Kandler O. Mode of action of glycine in the biosynthesis of peptidoglycan. $J$ Bacteriol 1973; 116: 1029-1053.

17. Marshall JH, Wilmoth GJ. Proposed pathway of triterpenoid carotenoid biosynthesis in Staphylococcus aureus: evidence from a study of mutants. J Bacteriol 1981; 147: 914-919.

18. Siegele DA, Kolter R. Life after log (minireview). J Bacteriol 1992; 174: 345-348. 